\title{
Klinisk nevrologisk undersøkelse av den geriatriske pasient
}

\begin{abstract}
Sammendrag
Bakgrunn. Nervesystemet gjennomgår en rekke fysiologiske endringer med $ø$ kende alder. Ved klinisk nevrologisk undersøkelse kan disse feiltolkes som uttrykk for patologiske forandringer i nervesystemet. Målsettingen med denne artikkelen er å gi en oversikt over nevrologiske utfall som kan ha sin årsak i normal aldring.
\end{abstract}

Materiale og metode. Manuskriptet bygger på ikke-systematisk søk i PubMed og forfatternes kliniske erfaring.

Resultater. Det er i liten grad aldersfysiologiske endringer når det gjelder kognitive funksjoner. Unntak er eksekutive funksjoner, psykomotorisk tempo og episodisk hukommelse, som reduseres med økende alder. For øvrig ses aldersfysiologiske endringer særlig i øyemotilitet i vertikalplanet ved blikk oppover, vibrasjonssans, akillesreflekser, primitivreflekser og motorisk tempo. Kraftprestasjoner reduseres med $20-40 \%$ hos friske personer over 70 år.

Fortolkning. Korrekt tolking av kliniske funn ved nevrologisk undersøkelse hos gamle forutsetter kunnskap om nervesystemets fysiologiske aldring. Dokumentasjonen vedrørende aldersfysiologiske endringer i nervesystemet er imidlertid mangelfull, og det er behov for videre forskning på dette feltet.

\section{Brynjar Fure}

brynjar.fure@kunnskapssenteret.no

Seksjon for spesialisthelsetjenen

Nasjonalt kunnskapssenter for helsetjenesten og

Geriatrisk avdeling

Oslo universitetssykehus, Ullevål

Erik Hauge Engebretsen

Medisinsk avdeling

Bærum sykehus

\section{Bente Thommessen}

Nevroklinikken

Akershus universitetssykehus

\section{Anne Rita Øksengård}

Institutionen för neurobiologi,

vårdvetenskap och samhälle

Karolinska Institutet

\section{Anne Brækhus}

Nevrologisk avdeling

Geriatrisk avdeling

Oslo universitetssykehus, Ullevål

Normal aldring medfører flere endringer i nervesystemet. Samtidig med disse endringene ses det i høy alder en økning i forekomsten av nevrologisk sykdom (1). Dette medfører at nevrologisk undersøkelse av gamle og tolking av funnene kan by på store utfordringer.

En korrekt nevrologisk diagnose forutsetter at man kan skille fysiologisk aldring fra patologiske forandringer $\mathrm{i}$ nervesystemet. Dersom fysiologiske forandringer oppfattes som patologiske, kan dette resultere $\mathrm{i}$ overdiagnostisering. Motsatt kan manglende kunnskap om normal aldring føre til underdiagnostisering. I begge tilfeller kan resultatet bli at pasienten ikke får fullgod behandling.

Andre årsaker til at det kan være vanskelig å skille «friskt» fra «sykt» hos gamle, er forekomsten av mer diffuse sykdomsbilder og høy komorbiditet.

I den klinisk nevrologiske undersøkelsen inngår momentene høyere hjernefunksjoner, hjernenerver, motilitet, sensibilitet, reflekser, gangfunksjon, muskeltonus og koordinasjon. I tillegg undersøkes hode, hals og nakke. Økt kunnskap om fysiologisk aldring i nervesystemet vil gjøre tolkingen av funnene ved den nevrologiske undersøkelsen enklere - ved at det blir lettere å skille «friskt» fra «sykt».

Formålet med denne artikkelen er å gi en oversikt over de utfall og endringer i nevrologisk status hos gamle som kan tillegges normal aldring.

\section{Materiale og metode}

Artikkelen bygger på ikke-systematisk søk i PubMed. Det er gjort et skjønnsmessig utvalg av artikler basert på forfatternes kliniske og forskningsmessige bakgrunn.

\section{Morfologiske aldersforandringer i hjernen}

Hjernens gjennomsnittsvekt er ca. $8 \%$ lavere hos 80-åringer enn hos 25-åringer, hvilket delvis kan forklares av nevrontap og redusert nevronstørrelse. Særlig blir hippocampus og frontallappene affisert $(2,3)$. Videre viser studier at normal aldring medfører en størrelsesøkning av hjernens ventrikler, spesielt sideventriklene (4), en sannsynlig reduksjon $i$ antall synapser og redusert synaptisk transmisjon (5). I tillegg reduseres blodgjennomstrømningen i deler av hjernen (3). Der er nå mulig å kvantifisere endringene $\mathrm{i}$ form og volum i hjernen ved hjelp av MR-teknikker og automatiserte målinger (4). For at nervefibrene skal fungere optimalt, er graden av myelinisering viktig. Studier har vist at myelinskjedene skades og får dårligere kvalitet med økende alder (6). Mens hjernebarken sett under ett viser en lineær reduksjon med økende alder, om enn med store lokale forskjeller, viser studier at det skjer en reduksjon i hvit substans først etter 40-50 års alder (7).

Den fysiologiske aldringens innvirkning på funn ved klinisk nevrologisk undersøkelse har vært relativt lite undersøkt. Et unntak fra dette er aldringens effekter på kognitiv funksjon. De eksisterende studier bygger på selekterte pasientpopulasjoner og har forskjellige inklusjons- og eksklusjonskriterier. Patologiske kliniske funn kan av noen klinikere tolkes som uttrykk for normal aldring, mens andre hevder de samme funnene er

\section{Hovedbudskap}

- Normal aldring i nervesystemet medfører en rekke endringer

- Tilsynelatende patologiske funn ved klinisk nevrologisk undersøkelse kan være uttrykk for normal aldring

- Spesiell oppmerksomhet må vises ved vurdering av øyemotilitet, senereflekser, vibrasjonssans, primitivreflekser, ekstrapyramidale funksjoner og eksekutive hjernefunksjoner 
sykdomsrelaterte. I én studie fant man at patologiske kliniske funn var svært vanlig ved nevrologisk undersøkelse av gamle og at ca. $30-50 \%$ av de nevrologiske utfallene ikke kunne forklares med underliggende sykdom (8), i en annen at alle nevrologiske utfall, bortsett fra redusert vibrasjonssans og ustøhet ved gange, var assosiert med nevrologisk sykdom (9).

\section{Hjernenerver}

Ved testing av pupillreaksjon og øyemotilitet avdekkes ofte flere utfall med økende alder, uten at disse nødvendigvis er patologiske. Pupillene er vanligvis mindre hos gamle og lysreaksjonen svakere, med redusert amplitude og hastighet (10). Odenheimer og medarbeidere avdekket fravær av pupillreaksjon hos opptil $19 \%$ av friske gamle (8).

Med stigende alder blir vinkelen ved vertikal øyemotilitet oppover redusert. Fra 80 års alder er den redusert med ca. $35 \%$ (11). Den vertikale øyemotiliteten nedover er i liten grad påvirket av pasientens alder. Dette må tas med i betraktningen når vertikal øyemotilitet oppover benyttes i diagnostikken av hjernedegenerative tilstander som f.eks. progredierende supranukleær parese. Ved denne tilstanden foreligger det parkinsonisme i kombinasjon med mer utbredt degenerasjon enn hva som ses ved Parkinsons sykdom, også i området rundt fjerde ventrikkel i bakre skallegrop.

Den vestibulookulære refleks blir mindre nøyaktig med økende alder (12). Optokinetisk nystagmus er fysiologiske øyebevegelser som oppstår når øyet ubevisst følger forbipasserende gjenstander. Øyet går da raskt tilbake til utgangsposisjonen for å følge en ny gjenstand, slik at en sakkadebevegelse oppstår. Denne funksjonen blir også tregere med alderen. Disse forandringene kan forårsake problemer med romlig orientering og gi redusert skarpsyn ved bevegelse.

Hørselstap av de høyfrekvente lydene, det vil si presbyacusis, er ofte en konsekvens av aldring. Presbyacusis er i hovedsak et hørselstap av nevrogen type (13). Graden av hørselstap er imidlertid svært varierende.

Luktesansen blir dårligere med alderen (14), trolig forårsaket av atrofi av n. olfactorius (15). I den senere tid er det også blitt fremsatt teorier om at redusert luktesans, eller mer korrekt redusert evne til luktidentifikasjon, også kan være en tidlig markør på nevrodegenerative lidelser som Alzheimers sykdom (16) og Parkinsons sykdom.

Utfall i de øvrige hjernenervene må i de fleste tilfeller klassifiseres som patologiske, da disse i liten grad utsettes for fysiologiske endringer ved økende alder.

\section{Motilitet og gange}

Kraftprestasjonene er ofte relativt velbevart hos eldre. En viss kraftsvikt forekommer likevel med økende alder. Etter 70 års alder er kraftprestasjonene redusert med 20-40\% hos friske personer, både i proksimal og dis-

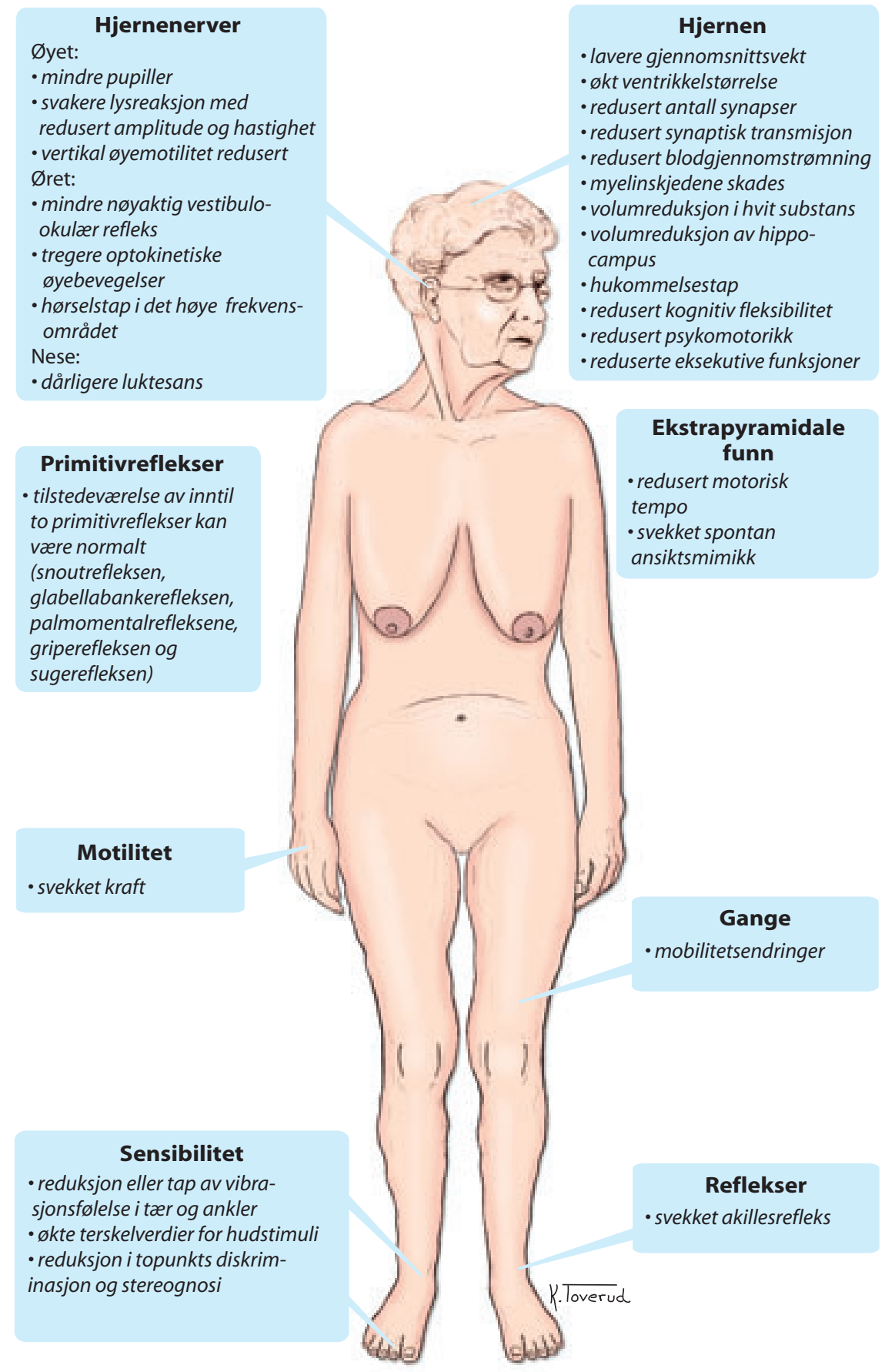

Figur 1 Endringer i nervesystemet ved normal aldring

tal muskulatur (17). Kraftreduksjonen skyldes reduksjon i antall muskelfibre og enkeltfibrenes størrelse. Reduksjonen beror i første rekke på tap av type 2-fibre («hurtige» fibre), som delvis erstattes av fett (17).

Mobilitetsendringer affiserer $14 \%$ i aldersgruppen $65-74$ år og så mye som $50 \%$ av dem over 85 år (18). Dette skyldes mange forhold, både av patologisk og fysiologisk art, blant annet cerebrale forandringer, men også forandringer i muskler og i det sensoriske apparat. Normal aldring bidrar til forandringer som likner Parkinsons sykdom, bortsett fra tremor, som alltid anses som patologisk (19).

\section{Sensibilitet}

Reduksjon eller tap av vibrasjonsfølelse i tær og ankler er vanlig hos gamle, og en reduksjon på 50-60\% kan ses hos personer over 80 år (20). Propriosepsjonen (leddsansen) er derimot bedre bevart.

Terskelverdiene for persepsjon av hudstimuli øker med stigende alder (20), men det kan være vanskelig å påvise denne endringen. Reduksjonen skyldes tap av myelin i sensoriske nerver. Forandringene i hudfølelse korrelerer med tap av sensoriske fibre, redusert amplitude av sensorisk nervepotensial og tap av dorsalrotganglieceller. En viss reduksjon i topunkts diskriminasjon og 
stereognosi er også rapportert (20), men her eksisterer det lite data.

\section{Reflekser}

Senerefleksene i overekstremitetene holder seg omtrent på samme nivå $i$ eldre år som $i$ yngre, det samme gjelder for patellarrefleksen. Derimot reduseres akillesrefleksene hos eldre i stor grad. Dette mener man skyldes redusert elastisitet i akillessenen, ikke nødvendigvis endringer i selve nerven eller refleksbuen (21).

Bowditch og medarbeidere undersøkte forekomsten av akillesrefleks hos 1074 friske voksne i alderen 16-100 år (21). De fant manglende bilateral akillesrefleks i aldersgruppene 61-70 år, 71-80 år, 81-90 år og 91-100 år på henholdsvis $30,0 \%, 36,6 \%$, $49,5 \%$ og 76,5 \%. Ensidig fravær av akillesrefleksen kan imidlertid oftest tolkes som uttrykk for patologisk forandring, mens bilateralt bortfall av akillesrefleksen ofte er fysiologisk etter 60 års alder.

\section{Primitivreflekser}

Primitivrefleksene omfatter snoutrefleksen (trutrefleksen), glabellabankerefleksen, palmomentalrefleksene, griperefleksen og sugerefleksen. Snoutrefleksen utløses ved å banke lett på over- eller underleppen. Positiv refleks innebærer at det oppstår en «trutning» (trutmunn). Glabellabankerefleksen utløses ved å banke lett på pannen, over og mellom øynene. Dersom man ikke reflektorisk inhiberer øyeblunking etter 2-3 bankinger, anses glabellabankerefleksen som positiv. Palmomentalrefleksene kan utløses ved å stryke i håndflaten, enten på tenar- eller hypotenarsiden. Samtidig kontraksjon av ipsilaterale $\mathrm{m}$. mentalis på haken er uttrykk for positiv palmomentalrefleks. Griperefleksen utløses ved å legge en gjenstand i pasientens hånd. Sugerefleksen utløses ved å stikke f.eks. en spatel i pasientens munn.

Primitivrefleksene er til stede på spedbarnsstadiet og forsvinner eller avtar betydelig rundt ett års alder (22). Det er imidlertid vist at disse refleksene kan være til stede hos $11-27 \%$ av friske $25-45$-åringer, hos $22-35 \%$ av friske 46-65-åringer og hos $21-47 \%$ av friske $66-82$-åringer (22). Inntil to utløsbare primitivreflekser kan være til stede hos nevrologisk friske personer (23), ved mer enn to øker risikoen for at pasienten også har kognitiv svikt av vaskulær eller primærdegenerativ årsak (23).

Kan vi ha praktisk nytte av primitivreflekser i klinisk praksis? Hos pasienter med påvist kronisk iskemi ved radiologisk hjerneundersøkelse kan utløsbare primitivreflekser innebære økt risiko for at det foreligger kognitiv svikt eller demens (23). På den annen side kan fravær av primitivreflekser hos personer med kognitiv svikt gi mistanke om «pseudodemens», f.eks. på grunn av depresjon eller legemiddelbivirkning (23). Ved parkinsonisme kan også utløsbare primitivreflekser styrke mistanken om mer utbredt hjernedegenerativ tilstand som lewylegemesykdom eller Parkinson pluss-syndrom, som f.eks. mutippel systematrofi (MSA) eller progredierende supranukleær parese (PSP), mens sannsynligheten for Parkinsons sykdom antakelig er mindre (24).

\section{Ekstrapyramidale funn}

Parkinsons sykdom (ekte paralysis agitans) kjennetegnes av hypokinesi, rigiditet, hviletremor og nedsatt postural kontroll. En rekke symptomer og funn kan, når de foreligger, tale for at hjernedegenerasjonen er mer utbredt enn det som er vanlig ved tidlig Parkinsons sykdom. Til disse hører debut av parkinsonistiske symptomer samtidig i både høyre og venstre kroppshalvdel, kognitiv svikt i tidlig stadium og manglende effekt av levodopa. Fravær av hviletremor kan også gi mistanke om at en pasient med ekstrapyramidale funn ikke lider av Parkinsons sykdom.

Ekstrapyramidale funn forekommer ikke bare hos personer med hjernedegenerativ tilstand, men også hos nevrologisk friske eldre. Nedsatt fingertapping, hæltapping og svekket spontan ansiktsmimikk kan ses hos $35-53 \%$ av friske personer over 80 år (25). Også flektert kroppsholdning og subbende gange foreligger hos en stor andel friske gamle (25). Rigiditet i armer og hviletremor er imidlertid nærmest ikke-eksisterende hos nevrologisk friske, selv i høy alder (25).

Det foreligger for øvrig lite forskningsbasert kunnskap om tonusendring i eldre år. Jenkyn skriver i sin artikkel fra 1989 at «basert på klinisk erfaring tenderer muskeltonus til å øke fra 70 års alder» (26).

\section{Undersøkelse av mental status}

I den nevrologiske undersøkelsen inngår også vurdering av bevissthetsnivå og kognitive funksjoner. Ved normal aldring skjer det et gradvis tap av synapser og deres nevronale nettverk samt en endring i lokale blodperfusjonsforhold som først og fremst påvirker kognitiv fleksibilitet og psykomotorikk. Hippocampus, som er særlig viktig for hukommelsesfunksjonen, spesielt evnen til nyinnlæring, blir redusert i størrelse med ca. $14 \%$ fra 20 til 90 års alder (7). Longitudinelle studier viser at $i$ aldersgruppen 65-90 år vil personer med lett globalt nedsatt kognitiv funksjon, inkludert redusert evne til å huske nylig innlært materiale, i større omfang utvikle demens enn de uten slike amnestiske symptomer $(27,28)$.

Kortikale funksjoner skal vurderes, inklusive frontal-, temporal-, parietal- og oksipitallappsfunksjoner.

Frontallappsfunksjoner omfatter oppmerksomhet, motivasjon, planlegging, gjennomføring, kontroll og atferd. Med temporallappsfunksjoner menes i denne sammenhengen innlæring, umiddelbar hukommelse, gjenkalling og utsatt hukommelse. Parietallappsfunksjonene inkluderer gjennomføring av sammensatte og basale aktiviteter samt orien- tering for rom og retning, mens parietooksipitallappsfunksjonene består av oppfattelse av visuell informasjon og gjenkjenning av ansikter og objekter. Utfall i kortikale funksjoner er i prinsippet alltid uttrykk for en patologisk tilstand, også i høy alder. Dette innebærer at afasi, apraksi, agnosi, neglekt og visuospatiale vansker som påvises ved nevrologisk undersøkelse, ikke kan tolkes som aldersfysiologiske endringer.

Det er stort sett enighet om at aldring normalt kan medføre reduksjon i deler av hukommelsesfunksjonen, spesielt episodisk hukommelse, hvor særlig evnen til nyinnlæring blir affisert. Dette gjenspeiles ofte ved problemer med å huske navn, tall, ansikter osv., uten at det nødvendigvis er patologisk.

Videre ses redusert psykomotorisk tempo, dvs. at eldre bruker lengre tid på å løse både enkle og mer sammensatte oppgaver. Imidlertid kan eldre ha stor effekt av å trene på spesifikke oppgaver og dermed nesten utlikne forskjellene mellom yngre og eldre (6).

Det må likevel vektlegges at det, som hos yngre, er betydelige individuelle variasjoner i de eldste aldersgruppene $(6,29)$. Det er viktig å huske på at disse endringene normalt inntreffer hos gamle, slik at man ikke stiller diagnosen mental svikt på feilaktig grunnlag. Kognitive screeningtester for ovennevnte funksjoner må derfor aldersnormeres. Dette gjelder f.eks. Trail Making Test (TMT) A og B (30), begge hyppig i bruk i klinisk virksomhet.

Ved en kartleggende undersøkelse anbefales å gjennomføre følgende enkle kognitive tester, som samlet gir en valid og objektiv vurdering av kortikale funksjoner: Mini Mental Status (MMS) (31), klokketest (32) og TMT A og B (30).

Ved hjelp av MMS undersøkes orientering for tid og sted, læring, kortidshukommelse, abstrakt tenkning, oppmerksomhet, benevning, gjennomføring av aktiviteter og visuospatiell orientering. MMS-sumskår påvirkes av bakgrunn, utdanning, stemningsnivå, syn og hørsel. Klokketesten (32) avdekker evnen til å være orientert for rom og retning, evnen til planlegging og gjennomføring av en praktisk oppgave samt logisk tenkeevne. Testen skaleres $0-5$, og skåres godkjent dersom 3 eller flere poeng oppnås. Ved hjelp av Trail Making Test A og B (30) undersøkes oppmerksomhet, psykomotorisk tempo og eksekutiv evne, sistnevnte innebærer evnen til å planlegge, starte, gjennomføre og avslutte en handling innenfor rimelig tid. TMT A og B er normert for alder (33).

Alle testresultater bør vurderes i lys av øvrig klinisk informasjon. Ved totalskår på de kognitive testene under forventet eller i usikker sone bør man komplettere utredningen med andre relevante undersøkelser.

\section{Konklusjon}

Mange tilsynelatende patologiske funn i nervesystemet kan hos gamle være uttrykk for fysiologisk aldring (fig 1). Man må der- 
for utvise forsiktighet ved vurdering og tolking av funn ved den klinisk nevrologiske undersøkelsen hos eldre pasienter, særlig ved utredning av mulig nevrodegenerativ tilstand. Ved nevrologisk undersøkelse av gamle kreves det spesiell årvåkenhet ved vurdering av øyemotilitet, senereflekser, vibrasjonssans, primitivreflekser, ekstrapyramidale funn og eksekutive funksjoner. Den nevrologiske forskningen har i stor grad vært rettet mot yngre personer. Det er derfor åpenbart et behov for etablering av standarder for nevrologisk undersøkelse av gamle.

\section{Brynjar Fure (f. 1959)}

er dr.med. og spesialist i nevrologi og indremedisin/geriatri. Han er forskningsleder ved Nasjonalt kunnskapssenter for helsetjenesten og overlege ved Seksjon for hjerneslag, Geriatrisk avdeling, Oslo universitetssykehus, Ullevål.

Ingen oppgitte interessekonflikter.

\section{Erik Hauge Engebretsen (f. 1974)}

er spesialist i indremedisin og geriatri og seksjonsoverlege generell medisin. Ingen oppgitte interessekonflikter.

\section{Bente Thommessen (f. 1954)}

er spesialist i nevrologi og dr.med. og tok doktorgraden på et arbeid om hjerneslag hos eldre. Hun er overlege ved slagenheten, Nevroklinikken, og har flere års erfaring innen geriatri.

Ingen oppgitte interessekonflikter.

\section{Anne Rita Øksengård (f. 1961)}

er spesialist $i$ indremedisin og geriatri. Ingen oppgitte interessekonflikter.

\section{Anne Brækhus (f. 1961)}

er spesialist i nevrologi. Hun har doktorgrad i tidligdiagnostikk av demens og er spesielt interessert i problemstillingen demens og førerkort. Arbeider ved Hukommelsesklinikken (Geriatrisk avdeling), Nevrologisk avdeling og i Helsedirektoratet.

Ingen oppgitte interessekonflikter.

\section{Litteratur}

1. Camicioli RM, Kaye JA, Brummel-Smith K. Recognition of neurologic diseases in geriatric inpatients. Acta Neurol Scand 1998; 97: 265-70.

2. Sletvold O. Hjernens aldring. I: Engedal K, Wyller TB, red. Aldring og hjernesykdommer. Oslo: Akribe Forlag, 2003: 33-43.

3. Brodal P. Sentralnervesystemet. 3. utg. Oslo: Universitetsforlaget, 2001: 173-7

4. Walhovd KB, Fjell AM, Reinvang I et al. Effects of age on volumes of cortex, white matter and subcortical structures. Neurobiol Aging 2005; 26: 1261-70, discussion 1275-8.

5. Anderton $\mathrm{BH}$. Ageing of the brain. Mech Ageing Dev 2002; 123: 811-7.

6. Hestad K. Normal og patologisk kognitiv aldring kan de skilles? Tidsskrift for Norsk Psykolologforening 2008; 45: 1133-42.

7. Walhovd KB, Fjell AM. Strukturert MR og kognitiv funksjon: hvordan henger endringer i hjerne og kognisjon sammen? Tidsskrift for Norsk Psykologforening 2008; 45: 1124-32.

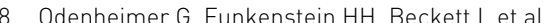
Comparison of neurologic changes in 'successfully aging' persons vs the total aging population. Arch Neurol 1994; 51: 573-80.

9. Waite LM, Broe GA, Creasey $\mathrm{H}$ et al. Neurological signs, aging, and the neurodegenerative syndromes. Arch Neurol 1996; 53: 498-502.

10. Bitsios P. Prettyman R, Szabadi E. Changes in autonomic function with age: a study of pupillary kinetics in healthy young and old people. Age Ageing 1996; 25: 432-8

11. Oguro H, Okada K, Suyama N et al. Decline of vertical gaze and convergence with aging. Gerontology 2004; 50 : 177-81.

12. Ward BK, Mohammed MT, Brach JS et al. Physical performance and a test of gaze stabilization in older adults. Otol Neurotol 2010; 31: 168-72.

13. Besdine RW, Wu D. Aging of the human nervous system: what do we know? Med Health R I 2008. 91: 129-31.

14. Lafreniere D, Mann N. Anosmia: loss of smell in the elderly. Otolaryngol Clin North Am 2009; 42: $123-31$.

15. Schiffman SS. Taste and smell losses in normal aging and disease. JAMA 1997; 278: 1357-62.

16. Murphy C. Loss of olfactory function in dementing disease. Physiol Behav 1999; 66: 177-82.

17. Doherty TJ. Invited review: Aging and sarcopenia. J Appl Physiol 2003; 95: 1717-27.

18. Sudarsky L. Gait disorders: prevalence, morbidity and etiology. Adv Neurol 2001; 87: 111-7.

19. Friedman JH. Gait in the elderly. Med Health R I 2008; 91: 134-5

20. Sirven JI, Malamut BL. red. Clinical neurology in the older adult. 2. utg. Amsterdam: Wolter Kluwers, 2008.

21. Bowditch MG, Sanderson P. Livesey JP. The significance of an absent ankle reflex. J Bone Joint Surg $\mathrm{Br} 1996 ; 78: 276-9$

22. van Boxtel MP, Bosma H, Jolles J et al. Prevalence of primitive reflexes and the relationship with cognitive change in healthy adults: a report from the Maastricht Aging Study. J Neurol 2006; 253 935-41

23. Di Legge S, Di Piero V, Altieri M et al. Usefulness of primitive reflexes in demented and non-demented cerebrovascular patients in daily clinical practice. Eur Neurol 2001; 45: 104-10.

24. Borroni B, Broli M, Costanzi C et al. Primitive reflex evaluation in the clinical assessment of extrapyramidal syndromes. Eur J Neurol 2006; 13 : $1026-8$

25. Prettyman R. Extrapyramidal signs in cognitively intact elderly people. Age Ageing 1998; 27: 557-60.

26. Jenkyn LR. Examining the aging nervous system. Semin Neurol 1989: 9: 82-7.

27. Petersen RC, Smith GE, Waring SC et al. Ageing, memory and cognitive impairment. Int Psychogeriatr 1997; 9 (suppl 1): 65-9

28. Boeve B, McCormick J, Smith G et al. Mild cognitive impairment in the oldest old. Neurology 2003, 60: 477-80

29. Allain P, Berrut G, Etcharry-Bouyx F et al. Executive functions in normal aging: an examination of script sequencing, script sorting, and script monitoring. J Gerontol B Psychol Sci Soc Sci 2007; 62: 187-90.

30. Reitan RM. The relation of the trail making test to organic brain damage. J Consult Psychol 1955; 19: $393-4$

31. Folstein MF, Folstein SE, McHugh PR. «Minimental state». A practical method for grading the cognitive state of patients for the clinician. J Psychiatr Res 1975; 12: 189-98.

32. Shulman KI, Gold DP, Cohen CA et al. Clock drawing and dementia in the community: a longitudinal study. Int J Geriatr Psychiatry 1993; 8: 487-96.

33. Lezak MD. Neuropsychological assessment. 2. utg. New York: Oxford University Press, 1983.

Mottatt 16.5. 2010, første revisjon innsendt 2.11. 2010, godkjent 3.3. 2011. Medisinsk redaktør Are Brean. 